model simultaneously, only AXC time was an important predictor of therapeutic use of pacing wires.

In our group of patients, no complications related to the placement, use, or removal of wires was noted. The 95\% CI around the estimate of complication rate is $0 \%$ to $1.2 \%$. None of the patients in whom wires were not placed experienced an arrhythmia. The surgeons were able to predict with $100 \%$ accuracy the patients not requiring pacing wires but only $26 \%$ (59/170) of those patients who would.

\section{Discussion}

This study found the incidence of use of pacing wires to be equal to $26 \%$ for post-CVS pediatric patients. Of those operations in which pacing wires were placed, the percentage of use increased to $35 \%$, with more than half $(56 \%)$ for diagnostic purposes.

When analysis was performed to evaluate the need for pacing wires (diagnostic, therapeutic, or both), 2 predictors fell out: length of $\mathrm{AXC}$ and $\mathrm{CPB}$ time. When the group of patients with pacing wires was further analyzed, therapeutic and diagnostic versus all other, significantly longer AXC and CPB times were noted as predictors. When comparisons were made between pacing wires used for therapeutic and diagnostic purposes, the only difference was in the AXC time (98.3 vs 65.7 minutes).

Although this study does not determine patients who require pacing wires, it does provide some guidelines. Patients whose
AXC times, CPB times, or both are longer might benefit from placing pacing wires at the time of CVS. With each 10-minute increase in $\mathrm{AXC}$ or $\mathrm{CPB}$ time, a significant increase, $27 \%$ and $13 \%$, occurred in the therapeutic use of pacing wires. These findings, longer AXC and CPB times, might simply be variables of the surgical complexity of the case. Despite anecdotal reports of complications associated with pacing wires, no complications were noted with the placement, use, or removal in this study.

Patients with longer CPB and AXC times associated with more complicated surgical procedures have a significantly higher chance of requiring pacing wires for their postoperative management. In addition, their placement, use, and removal appear to be safe.

\section{References}

1. Pfammatter JP, Bachmann DCG, Wagner BP, et al. Early postoperative arrhythmias after open heart procedures in children with congenital heart disease. Pediatr Crit Care Med. 2001;2:217-22.

2. Valsangiacomo E, Schmid ER, Schupbach RW, et al. Early postoperative arrhythmias after cardiac surgery in children. Ann Thorac Surg. 2002;74:792-6.

3. Delaney J, Moltedo J, Dziura JD, et al. Early postoperative arrhythmias after cardiac surgery in children. J Thorac Cardiovasc Surg. 2006;131: 1296-1300.

\title{
Hybrid approach as a bridging procedure to biventricular repair for aortic hypoplasia with ventricular septal defect in a 1720-g premature infant
}

Pedro Betrián Blasco, MD, ${ }^{\text {a }}$ Josep Girona Comas, MD, ${ }^{\text {a }}$ Arturo Gonçalves Estella, MD, ${ }^{\text {b }}$ Queralt Ferrer Menduña, MD, ${ }^{a}$ María Concepción Céspedes Dominguez, MD, ${ }^{c}$ Joan Balcells Ramirez, MD, ${ }^{d}$ Begoña Manso García, MD, ${ }^{a}$ and Ferrán Gran Ipiña, MD, ${ }^{a}$ Barcelona, Spain

廿 ypoplastic left heart syndrome varies from mitroaortic atresia and a diminutive left ventricle to milder forms of mitroaortic stenosis with a reasonable-sized left ventricle.

\footnotetext{
From the Pediatric Cardiology and Hemodynamics Department, ${ }^{a}$ the Pediatric Cardiac Surgery Department, ${ }^{\mathrm{b}}$ Neonatology, ${ }^{\mathrm{c}}$ and the Pediatric Intensive Care Unit, "Valle de Hebrón Hospital," Barcelona, Spain.

Received for publication March 22, 2007; revisions received April 16, 2007; accepted for publication April 23, 2007.

Address for reprints: Pedro Betrián Blasco, $\mathrm{MD}, \mathrm{C} /{ }^{\mathrm{a}}$ Arquitecto Moragas 18 esc a $4^{\circ}$ 2a, Barcelona CP 08035, Spain (E-mail: pedrobetrian@yahoo.es).

J Thorac Cardiovasc Surg 2007;134:516-8

$0022-5223 / \$ 32.00$

Copyright $\odot 2007$ by The American Association for Thoracic Surgery doi:10.1016/j.jtcvs.2007.04.005
}

\section{Clinical Summary}

A female infant with fetal diagnosis of aortic atresia was born at 34 weeks of gestation weighing $1620 \mathrm{~g}$. At birth, echocardiography was carried out, showing a double-outlet right ventricle with great vessels side to side and aorta on the right and a large subpulmonary ventricular septal defect. The aorta was extremely hypoplastic, with a minimal anterograde blood flow. The aortic arch was also hypoplastic and filled with retrograde blood flow from the ductus. The left ventricle and mitral valve were in normal values. Prostaglandin $\mathrm{E}_{1}$ infusion was started.

When she was 25 days old, weighing $1720 \mathrm{~g}$, a median sternotomy was performed. First, pulmonary artery branches were banded at their origin (polytetrafluoroethylene bands,* diameter of $2.8 \mathrm{~mm})$. Next, two self-expandable stents $(6 \times 12 / 6 \times 18 \mathrm{~mm})$ were placed through the main pulmonary artery puncture to cover

*Gore-Tex band, registered trademark of W. L. Gore \& Associates, Inc, Newark, Del. 


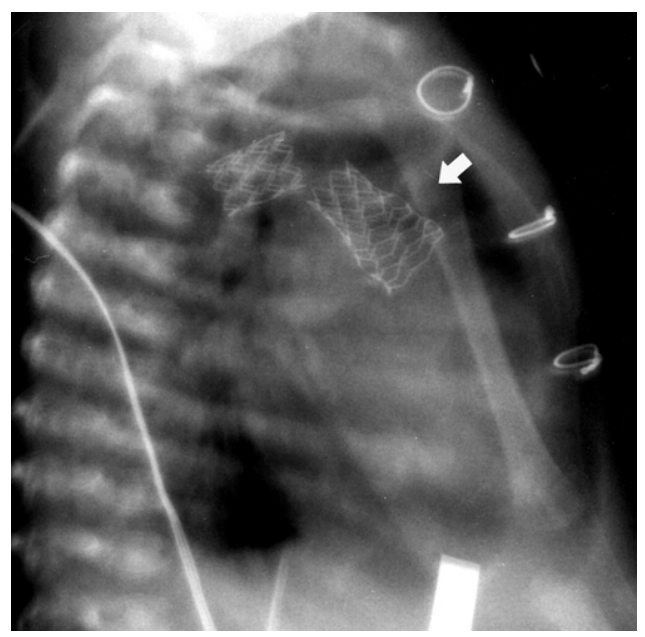

Figure 1. Stent migration into the main pulmonary artery (white arrow).

the entire ductus. The procedure was uneventful, and the final oxygen saturation was $85 \%$ to $90 \%$.

Seven days after the procedure, one stent was found displaced into the main pulmonary artery, generating a mild pulmonary regurgitation (Figure 1), and was successfully removed through a purse-string suture of the main pulmonary artery with caval occlusion (30 seconds).

Two months later, in a routine control, she weighed $2420 \mathrm{~g}$ and presented with an oxygen saturation of $80 \%$, normal blood pressures in the extremities, and a normal rest echocardiogram but a stress echocardiogram with generalized ST depression. Echocardiography was carried out showing a moderate stenosis of blood flow from the stent to both the preductal and postoductal aorta. Emergency balloon dilation was performed successfully, removing the stenosis (Figure 2).

At the age of 5 months, weighing $4900 \mathrm{~g}$ and with an oxygen saturation of $70 \%$ to $75 \%$, she underwent surgical biventricular correction. A Norwood-type reconstruction of the aortic arch (expanded with a homograft patch until beyond ductal insertion), debanding of the pulmonary arteries (angioplasty was not necessary), ductus and stent removal (minimal fibrosis was found and easily removed), and a Rastelli-type procedure (transpulmonary ventricular septal defect closure with a homograft patch and a right ventricle-pulmonary artery connection with a 10 -mm valved homograft conduit) were carried out. The postoperative period was complicated with the presence of low cardiac output requiring extracorporeal membrane oxygenation support for 3 days, with no other major events.

\section{Discussion}

Aortic atresia or severe aortic hypoplasia is usually associated with left ventricular hypoplasia; however, in $4 \%$ to $7 \%$ of these patients, a ventricular septal defect might exist, allowing an appropriate outflow for the ventricle and an opportunity for normal growth and biventricular repair. ${ }^{1}$ Two approaches have been proposed: a staged approach with an initial Norwood procedure and delayed biventricular repair or a primary correction. ${ }^{2}$ The staged procedure

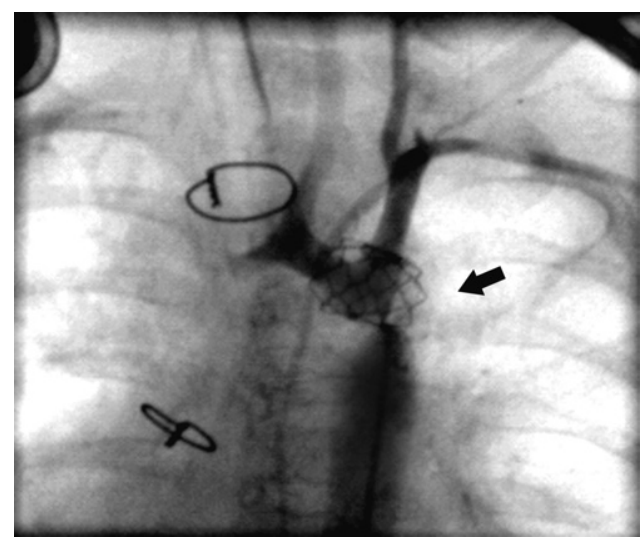

Figure 2. Aortic coarctation between the ductal stent and aorta (black arrow).

avoids the need for a ventriculotomy and placement of a right ventricular conduit in these small neonates and is a repair of lesser magnitude, but persistence of a parallel circulation and a significant interstage mortality has been advocated to introduce neonatal repair. ${ }^{1-3}$ Recent series report good results of primary correction, but staged procedure series also show excellent results. ${ }^{1,2}$ Despite recent improvement, the Norwood stage I operation remains a high-risk procedure, facing a mortality of $20 \%$ to $50 \%$ when risk factors, such as birth weight of less than $2.5 \mathrm{~kg}$, are present. ${ }^{4}$ In the last years, some groups have developed hybrid procedures, with ductal stenting and pulmonary artery banding improving results in high-risk patients and avoidance of neurological complications associated with neonatal prolonged cardiopulmonary bypass. ${ }^{4} \mathrm{Hy}-$ brid procedures allow a variety of posterior surgical strategies: heart transplantation (extending the waiting period), biventricular repair (with a period to follow left ventricular evolution and viability), or the Norwood procedure together with the bidireccional Glenn procedure (with the possibility of percutaneous Fontan completion). ${ }^{4,5}$ Some complications associated with the hybrid procedure have been described, such as closure of atrial septal defect, stenosis of pulmonary arteries, stent migration, arch perforation, and coarctation. In our case, the low birth weight forced us to choose a staged approach, and given that even the Norwood stage I procedure alone presents a high surgical risk in these patients, we chose a hybrid procedure with ductal stenting and pulmonary artery banding as a bridge to a posterior biventricular repair. In our patient, stent migration and aortic coarctation were precociously detected because of a close surveillance and resolved with surgical removal and balloon angioplasty. The hybrid procedure could be a good option in this type of patient, allowing a late repair with lower risks, but a close surveillance is needed to precociously detect any complication.

\section{References}

1. Nathan M, Rimmer D, Del Nido PJ, Mayer JE, Bacha EA, Shin A, et al. Aortic atresia or severe left ventricular outflow tract obstruction with ventricular septal defect: results of primary biventricular repair in neonates. Ann Thorac Surg. 2006;82:2227-32. 
2. Gruber PJ, Fuller S, Cleaver KM, Abdullah I, Gruber SB, Nicholson SC, et al. Early results of single-stage biventricular repair of severe aortic hypoplasia or atresia with ventricular septal defect and normal left ventricle. J Thorac Cardiovasc Surg. 2006;132: 260-3.

3. Ohye RG, Kagisaki K, Lee LA, Mosca RS, Goldberg CS, Bove EL. Biventricular repair for aortic atresia of hypoplasia and ventricular septal defect. J Thorac Cardiovasc Surg. 1999;118:648-54.
4. Bacha EA, Daves S, Hardin J, Abdulla R, Anderson J, Kahana M, et al. Single-ventricle palliation for high risk neonates: the emergence of an alternative hybrid stage I strategy. J Thorac Cardiovasc Surg. 2006; 131:163-71.

5. Michel-Behnke I, Akintuerk H, Marquardt I, Mueller M, Thul J, Bauer $\mathrm{J}$, et al. Stenting of the ductus arteriosus and banding of the pulmonary arteries: basis for various surgical strategies in newborns with multiple left heart obstructive lesions. Heart. 2003;89:645-50.

\section{Anomalous origin of the left main artery from the pulmonary artery: Adult presentation with systemic collateral supply and giant right coronary artery aneurysm}

Pietro Bajona, MD, ${ }^{a}$ Daniele Maselli, MD, ${ }^{\text {a }}$ Roberto Dore, MD, ${ }^{\mathrm{b}}$ and Gaetano Minzioni, MD, ${ }^{a}$ Pisa and Pavia, Italy

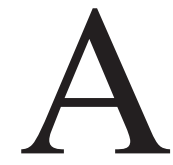

nomalous origin of the left coronary artery (LCA) from the pulmonary artery (ALCAPA) in adulthood is rare, and clinical presentation depends on collateral circulation between and to the coronary arteries. We present an adult patient with ALCAPA with systemic collateral supply to the LCA and a giant right coronary artery (RCA) aneurysm who was successfully treated by means of closure of the anomalous origin of the left main artery and repair of the aneurysm.

\section{Clinical Summary}

A 44-year-old male physician was referred to our hospital because of a 6-month history of dizziness and increasing dyspnea on exertion. He had been a rugby player since childhood and had played semiprofessionally until a year before. He smoked 10 cigarettes per day, and he had no other risk factors for coronary artery disease. The results of physical examination were normal. Blood pressure was within normal limits. Laboratory test results were normal. Chest radiography revealed the presence of a moderate cardiomegaly and opacity overlapping the right heart border and the right pulmonary hilum. Electrocardiography revealed sinus

From the Cardiothoracic Department, ${ }^{a}$ Azienda Ospedaliera Universitaria Pisana, Pisa, Italy; and the Department of Radiology, ${ }^{\mathrm{b}}$ University Hospital of Pavia, Pavia, Italy.

Received for publication March 26, 2007; accepted for publication April 20, 2007.

Address for reprints: Pietro Bajona, MD, Cardiothoracic Department, Azienda Ospedaliera Universitaria Pisana, Via Paradisa 2, 56124 Pisa, Italy (E-mail: pietro.bajona@libero.it).

J Thorac Cardiovasc Surg 2007;134:518-20

$0022-5223 / \$ 32.00$

Copyright $\odot 2007$ by The American Association for Thoracic Surgery doi:10.1016/j.jtcvs.2007.04.016 rhythm and left ventricular hypertrophy with normal patterns of PR, QT, and ST segment.

Transthoracic echocardi-

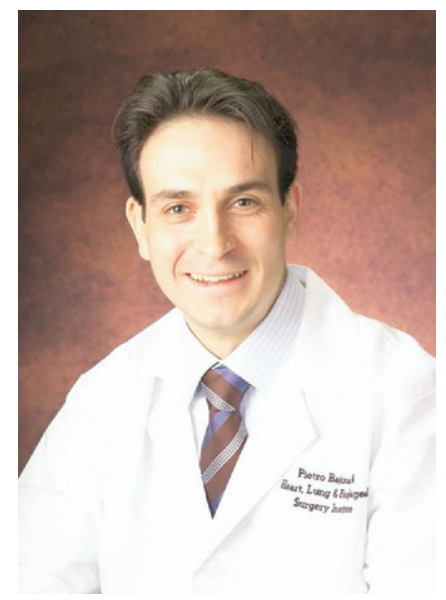

Dr Bajona ography showed a $7.0 \times$

$9.0-\mathrm{cm}$ aneurysm involving the proximal RCA and wide ectasia of the coronary arteries. At Doppler scanning, a fistula between the left main artery and the main pulmonary artery (MPA) was observed.

Coronary angiography showed that the LCA was supplied through aneurysmal collateral branches from the RCA and from both anomalous branches of the right internal thoracic artery (RITA) and bronchial artery (BA; Figure 1). Retrograde filling of the LCA and MPA was observed by injecting the distal RCA. Chest computed tomographic scanning with contrast demonstrated a large aneurysm of the proximal portion of the RCA. The distal RCA was dilated and tortuous (Figure 2). At the time of the operation, a giant RCA aneurysm and a dilated and tortuous anterior interventricular artery were found. The aneurysm was located laterally to the ascending aorta and anterior to the superior vena cava. Both abnormal branches from the RITA and BA were not visible. Hypothermic $\left(26^{\circ} \mathrm{C}\right)$ right femorofemoral cardiopulmonary bypass was established. The ascending aorta was clamped, and antegrade, cold, intermittent blood cardioplegia was delivered into the aortic root.

The MPA was transected just above the sinotubular junction. Massive backflow originating from the RCA and RITA and BA branches was observed draining into the MPA. Cardiopulmonary bypass was arrested for 2 minutes to permit the identification and ligation of the LCA ostium with a 4-0 polypropylene running suture.

The RCA aneurysm was transected and replaced with a 3-cmlong segment of an 8-mm-diameter Dacron graft. After patient rewarming, deairing was performed, the aortic crossclamp was released, and the operation was completed in a routine fashion. 